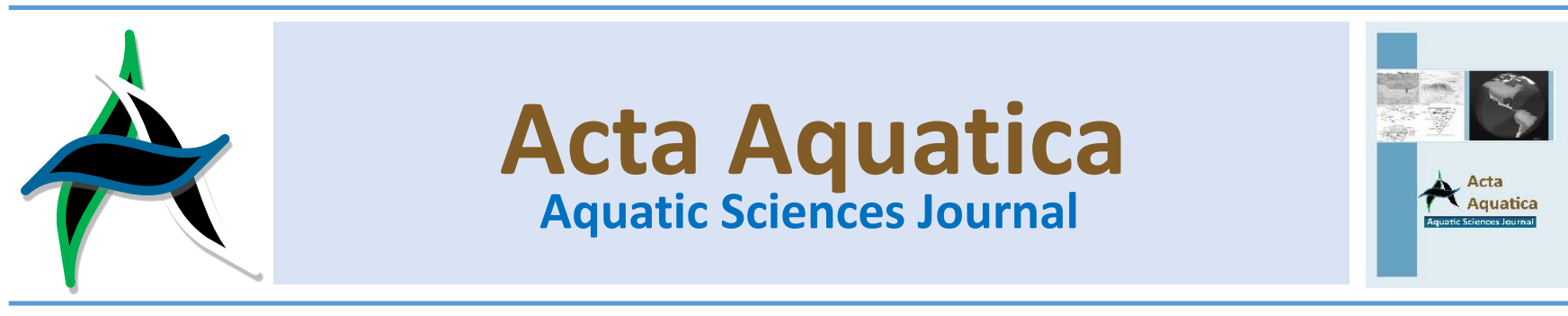

\title{
Effects of ascorbic acid and erythorbic acid on melanosis and quality in different shrimp species
}

\author{
Bülent Toktas a , and Nalan Gokoglu ${ }^{b, *}$ \\ ${ }^{a}$ Aksu Directorate of district Agriculture and Forestry. Antalya, Turkey \\ ${ }^{\text {b } A k d e n i z ~ U n i v e r s i t y, ~ F i s h e r i e s ~ F a c u l t y . ~ A n t a l y a, ~ T u r k e y ~}$
}

\begin{abstract}
With this study, ascorbic acid and erythorbic acid were used for the first time to prevent melanosis in shrimp. Three shrimp species (Aristaeomorpha foliacea, Plesionika edwardsi and Melicertus hathor) were used. It was determined that melanosis scores were higher in the control groups. Combination of ascorbic acid and erythorbic acid with metabisulphite was found to be more effective in inhibiting of melanosis than the application alone. No significant differences were found between the groups in terms of TVB-N values. The TMA$\mathrm{N}$ value of the control group was significantly higher than those of application groups. Ascorbic acid, Erythorbic acid and their combinations with sodium metabisulphite were found effective on inhibition of melanosis and quality changes in three shrimp species.
\end{abstract}

Keywords: reducing agents; ascorbic acid; erythorbic acid; melanosis; quality; shrimp

\section{Introduction}

Shrimps are easily degradable products due to microbial spoilage and melanosis (Martinez-Alvarez et al., 2005). After fishing, colour changes occur in the shell segments of the shrimps, especially in the carapace, with the effect of environmental factors (sun, temperature, etc.). In this formation, as well as environmental factors, the late removing of the head after catching and no or insufficient cooling of the material are effective. This colour change is called "melanosis" or "Blackspot (Erkan et al., 2007). This is one of the most important problems of the shrimp industry. In the formation of melanosis, phenols are oxidized to the quinones by the enzyme polyphenol oxidase. This mechanism is followed by nonenzymatic polymerization of quinones, which causes high molecular weight and dark or black pigments (Montero et al., 2005). Although these pigments are not hazardous to human health, they are not preferred by the consumer because they cause bad appearance (Montero et al., 2004). Researchers have conducted various studies to prevent melanosis by different inhibitors. Sulphides have been used as major inhibitors of melanosis worldwide. However, because of the frequent allergic reactions that cause health problems in humans, it is being investigated whether there are natural alternatives to the

\footnotetext{
* Corresponding author: Faculty of Fisheries, Akdeniz University, 07058. Antalya, Turkey. FAX: +902422262013
}

e-mail:ngokoglu@akdeniz.edu.tr

doi: $h$ ttp://doi.org/10.29103/aa.v7i2.2527 chemical compounds used to prevent melanosis (Benjakul et al., 2006).

Melanosis inhibitors are grouped according to their field of activity. These are acidifiers, chelating agents, reducing agents and enzyme inhibitors. Ascorbic acid acts as an oxygen scavenger to reduce molecular oxygen. Inhibition mechanism of ascorbic acid is the reduction of orthoquinones to diphenols. In addition, it delays blackening by oxidizing to dehydroascorbic acid (Golan-Goldhirsh et al., 1984). Erythorbic acid is the stereoisomer of L-ascorbic acid and is used as an antioxidant in various processed foods (Clark et al., 2009). Erythorbic acid was found to be effective in preventing the blackening of apple slices when used with $1 \%$ citric acid (Sapers \& Ziolkowski, 1987). There are studies on the use of erythorbic acid on fruits and vegetables to prevent the browning (Sapers \& Ziolkowski, 1987; Sapers et al., 1989; Sapers et al., 1990; Osuga et al., 1994; Santerre et al., 1988). However, there have been no studies on the use of shrimps.

On the other hand, the development of melanosis in shrimps is reported to differ between species. It is reported that this difference is due to substrate level, enzyme concentration and enzyme activity (Montero et al., 2001; Simpson et al., 1987). The severity of melanosis formation in crustaceans varies with species due to differences in substrate and enzyme concentration (Benjakul et al., 2005; Nirmal \& Benjakul, 2012). Therefore, in this study, it was aimed to investigate the effect of ascorbic acid and erythorbic acid on the development of melanosis in different shrimp species. For this purpose, the combination of sulphide application, known as the best 
melanosis inhibiting agent and the effects of combinations of reducing agents and sulphate have been tried.

\section{Materials and methods}

\subsection{Material}

In this study, shrimps (Aristaeomorpha foliacea, Plesionika edwardsi and Melicertus hathor) caught from the Gulf of Antalya, Turkey were used as material. The shrimps were obtained directly from fisherman immediately after the catching. A. foliacea and $P$. edwardsi were obtained by catching with commercial trawlers. Trawl shootings were made at a depth of $200-400 \mathrm{~m}$. M. hathor was caught with the shrimp nets. Fishing was done at 10-50 m depths. Each shrimp species were supplied as $20 \mathrm{~kg}$. Average carapace lengths of Aristaeomorpha foliacea, Plesionika edwardsi and Melicertus hathor were 46.31 $\mathrm{mm}, 18.24 \mathrm{~mm}$ and $35.2 \mathrm{~mm}$ respectively. The shrimps were transferred to the laboratory in the cold carrying bag with crushed ice immediately after landing.

\subsection{Treatments}

Upon arrival at the laboratory, they were divided into 10 different groups. Nine different solutions were prepared. The concentrations of the solutions were determined by preliminary experiments. After the preparation of the solutions, the shrimps were immersed in the solutions of $15^{\circ} \mathrm{C}$ (1:2 shrimp per solution) for $5 \mathrm{~min}$. Fluids of shrimps immersed in solutions were drained on the paper towel for 5 minutes and then placed on styrofoam plates and stored at $+4^{\circ} \mathrm{C}$. Melanosis development was investigated at 24 hours intervals during storage. $\mathrm{L}^{*}, \mathrm{a} *, \mathrm{~b}$ * colour values of the same samples were measured and quality control analyses were performed every 24 hours.

The experimental groups are as follows. $\mathrm{A} 2=$ Ascorbic $\operatorname{acid}(2 \%) ;$ A4 = Ascorbic acid (4\%); E2 = Erythorbic acid (2\%); E4 $=$ Erythorbic acid (4\%); $\mathrm{S}=$ Sodium metabisulphite solution $(1.25 \%) ;$ A2S = Ascorbic acid $(2 \%)+$ Sodium metabisulphite (1.25\%); A4S = Ascorbic acid (4\%) + Sodium metabisulphite(1.25\%); E2S = Erythorbic acid (2\%) + Sodium metabisulphite (1.25\%); E4S= Erythorbic acid $(4 \%)+$ Sodium metabisulphite (1.25\%); C = Control

\subsection{Melanosis measurement}

The development of melanosis was evaluated by five experienced panellists using the scale developed by Otwell and Marshall (1986). The panellists (three females and two males) from the staff members in the Fisheries Faculty conducted the panel. Panellists were aged between 25 and 50, had experience in evaluating shrimp quality, and were accustomed to consuming. Shrimps dipped in solutions containing antimelanotic agents were evaluated daily by panellists. Each sample was coded in random letters before the panel starts.

The values on the scale developed by Otwell and Marshall (1986) are expressed as follows: $0=$ absent; $2=$ slight, noticeable on some shrimp; $4=$ slight, noticeable on most shrimp; 6 = moderate, noticeable on most shrimp; $8=$ heavy, noticeable on most shrimp; $10=$ heavy, totally unacceptable.

\subsection{Total volatile basic nitrogen (TVB-N)}

After the $10 \mathrm{~g}$ homogenized sample was taken into the flask, $1 \mathrm{~g}$ of magnesium oxide and 1-2 drops of silicone defoamer were added. Samples were distilled and the distillate was collected in a flask containing $10 \mathrm{ml}$ of $0.1 \mathrm{~N} \mathrm{HCL}$. After distillation, the content was titrated with $0.1 \mathrm{~N} \mathrm{NaOH}$ using tashiro indicator (Schormüller, 1968).

\subsection{Trimethylamine nitrogen (TMA-N)}

A $10 \mathrm{~g}$ sample was blended with $90 \mathrm{~mL}$ of $5 \%$ trichloracetic acid (TCA) using an ultraturrax homogenizer (IKA Labortechnic, Staufen, Germany) and filtered. A $4 \mathrm{~mL}$ aliquot was transferred into test tubes and $1 \mathrm{~mL}$ formaldehyde (20\%), $10 \mathrm{~mL}$ anhydrous toluene, $3 \mathrm{~mL} \mathrm{KOH} \mathrm{(50 \% )} \mathrm{solutions} \mathrm{were}$ added. The tubes were shaken and a $5-\mathrm{mL}$ toluene layer was pipetted, to which a $5 \mathrm{~mL}$ picric acid $(0.02 \%)$ had been added. The supernatant was then transferred to a spectrophotometric cell. Absorbance at $410 \mathrm{~nm}$ was measured with a UV-Vis spectrophotometer (Shimadzu UV-160A). At the same time, a series of standards were prepared and measured (Schormüller, 1968).

\subsection{Colour measurements}

Colour values were measured using the CR-400 Minolta Chroma-meter (Minolta, Osaka, Japan). Before use, the device was calibrated with a white standard magnesium oxide plate. Colour measurements were measured in 3 different parts (carapace, body and tail) in shrimps and the results were given as mean values. $\mathrm{L}^{*}$ (brightness), $\mathrm{a}^{*}$ (redness) and $\mathrm{b} *$ (yellowness) values were measured in the samples.

\subsection{Statistical analysis}

In the homogenized samples, the analyses were carried out in two parallels and the experiments were carried out with two replications. Variance analysis was applied to the results obtained from the determined trial plan and the different applications were subjected to Duncan's multiple comparison tests and the results were evaluated statistically (Sokal \& Rohlf, 2012).

\section{Result and discussion}

\subsection{Result}

\subsubsection{Development of melanosis}

It was determined that melanosis values increased significantly $(p<0.01)$ with the storage time and reached the highest value in fourth day. There was a significant difference $(p<0.01)$ between the application groups in terms of melanosis values (Table 1).

Combination of ascorbic acid and erythorbic acid with metabisulphite was found to be more effective than the application alone. Sulphite combinations had similar effects to sulphite alone. It was determined that melanosis scores were higher in the control group than the other groups. When used alone, erythorbic acid and ascorbic acid were not very effective in preventing melanosis in shrimps. However, it was effective when used together with sulphide. When we compare erythorbic acid and ascorbic acid in terms of efficacy, it is seen that erythorbic acid is more effective. Concentration was significantly effective in preventing melanosis development. The concentration of $4 \%$ of reducing agents was found to be more effective than $2 \%$. When the shrimp species were compared, the lowest melanosis scores were determined for $P$. edwardsi $(p<0.01$ ), followed by $A$. foliacea and $M$. hathor 
Table 1

Effects of treatment methods, shrimp species and storage time interaction on melanosis scores in shrimps ${ }^{1-2}$

\begin{tabular}{|c|c|}
\hline Factors & Parameters \\
\hline \multicolumn{2}{|l|}{ Treatments $^{3}$} \\
\hline$A 2(n=12)$ & $3.18 \mathrm{~b}$ \\
\hline A4 (n=12) & $2.46 \mathrm{dc}$ \\
\hline$E 2(n=12)$ & $2.55 c$ \\
\hline E4 $(n=12)$ & 2.34dce \\
\hline$S(n=12)$ & $1.46 f$ \\
\hline A2S $(n=12)$ & $1.88 \mathrm{fe}$ \\
\hline$A 4 S(n=12)$ & $1.80 \mathrm{fe}$ \\
\hline E2S $(n=12)$ & $2.0 \mathrm{dfe}$ \\
\hline E4S $(n=12)$ & $1.98 \mathrm{dfe}$ \\
\hline$C(n=12)$ & $4.30 \mathrm{a}$ \\
\hline $\mathrm{SE}^{4}$ & 0.1 \\
\hline \multicolumn{2}{|l|}{ Shrimp species ${ }^{5}$} \\
\hline A. foliacea $(\mathrm{n}=40)$ & $2.92 a$ \\
\hline P. edwatdsi $(n=40)$ & $1.12 \mathrm{~b}$ \\
\hline M. hathor $(\mathrm{n}=40)$ & $3.14 \mathrm{a}$ \\
\hline $\mathrm{SE}^{4}$ & 0.1 \\
\hline \multicolumn{2}{|l|}{ Storage time (day) ${ }^{6}$} \\
\hline $1(n=30)$ & $0.95 d$ \\
\hline $2(n=30)$ & $2.01 \mathrm{c}$ \\
\hline $3(n=30)$ & $3.02 b$ \\
\hline $4(n=30)$ & $3.60 \mathrm{a}$ \\
\hline $\mathrm{SE}^{4}$ & 0.1 \\
\hline
\end{tabular}

1 Means within the same factor and the same column with different letters $(a, b$, $c$, d) are different $(p<0.01)$

2 Each number represents the average value of each parameter for all samples of the same treatment

3 E2= Erythorbic acid (2\%); E4= Erythorbic acid (4\%); A2= Ascorbic acid (2\%); A4= Ascorbic acid (4\%); S= Sodium metabisulphite; E2S=E2 + S; E4S=E4 + S; A2S=A2 $+\mathrm{S} ; \mathrm{A} 4 \mathrm{~S}=\mathrm{A} 4+\mathrm{S} ; \mathrm{C}=$ Control

$4 \mathrm{SE}=$ Standard Error

${ }^{5}$ Each number represents the average value of each parameter for all samples of the same shrimp species.

6 Each number represents the average value of each parameter for all samples with the same storage time.

\subsubsection{Quality changes}

TVB-N values increased with increase in storage time $(p<0.01)$ and reached the highest value on day 4 (Table 2 ). No significant difference was found between the groups in terms of TVB-N values $(p>0.01)$. Since all groups and all storage days are evaluated together for variance analysis, the difference between applications is insignificant. On the last day of storage, lower TVB-N results were obtained with the use of E2, sulphide and sulphide combinations for $A$. foliacea, A4, A2S and A4S for $P$. edwardsi, $\mathrm{A} 2$ and $\mathrm{A} 4$ for $M$. hathor. When the shrimp species were compared, the highest TVB- $N$ value was determined as $P$. edwardsi and the TVB-N values of $A$. foliacea and $M$. hathor species were found to be lower $(p<0.01)$. No significant difference was observed between the TVB-N values of $A$. foliacea and $M$. hathor species. It was observed that the TVB-N values of $P$. edwardsi, in particular, exceed the consumption limit value on the 4 th day of storage.

The TMA-N value of the control group was significantly higher than the TMA-N values of the application groups $(p<0.01)$. There was no significant difference in TMA-N content between treatment groups (Table 2). On the last day of storage, the applications of $\mathrm{A} 2, \mathrm{~A} 4, \mathrm{~A} 2 \mathrm{~S}$ and $\mathrm{A} 4 \mathrm{~S}$ resulted in lower TMA$\mathrm{N}$ in $A$. foliacea, while E2S, E4S, A2S and A4S applications for $P$. edwardsi and E4S and A4S applications for M. Hathor were found more effective. When the shrimp species were compared, the lowest $(p<0.01)$ TMA- $N$ values were determined in $M$. hathor and the TMA-N values of $A$. foliaceae and $P$. edwardsi species were higher $(\mathrm{p}<0.01)$. No significant difference was observed between the TMA-N values of $A$. foliacea and $P$. edwardsi species ( $p>0.01)$.

In this study, colour values $\left(L^{*}, a^{*}, b^{*}\right)$ of shrimp samples were measured. There was no significant difference between the groups $(p>0.01)$ in terms of $L^{*}$ values indicating the brightness or lightness value (Table 2 ). The values of $a^{*}$ were found to be the lowest $(p<0.01)$ in the control group shrimps, whereas in the other application groups, higher values were found (Table 2). The highest $b^{*}$ values were observed in groups where ascorbic acid and erythorbic acid were used alone. The lowest $b^{*}$ values were determined in metabisulphite treated group (Table 2 ) when shrimp species were compared, While the highest $a^{*}$ and $b^{*}$ values $(p<0.01)$ were found in $A$. foliacea, the highest $L^{*}$ value was found in $P$. edwardsi. The lowest $a^{*}$ and $b^{*}$ values $(p<0.01)$ were found in $M$. hathor, $L^{*}$ values in $A$. foliacea. The $L^{*}$ and $b *$ values showed a significant increase $(p<0.01)$ with the storage time and reached the highest value on the 4 th day. On the contrary, the $a^{*}$ values decreased with storage time and showed the lowest values on the 2 nd and 4 th days.

Table 2.

Effect of treatment methods, shrimp species and storage time interaction on quality parameters of shrimps ${ }^{1}$.

\begin{tabular}{|c|c|c|c|c|c|}
\hline \multirow{2}{*}{ Factors } & \multicolumn{5}{|c|}{ Parameters } \\
\hline & TVB-N² & TMA-N ${ }^{2}$ & $\mathrm{~L}^{*}$ & $a^{*}$ & $\mathrm{~b}^{*}$ \\
\hline \multicolumn{6}{|l|}{ Treatmnets ${ }^{3-4}$} \\
\hline$A 2(n=9)$ & $20.51 a$ & $2.34 b$ & $36.29 \mathrm{ba}$ & $7.31 \mathrm{a}$ & $6.67 \mathrm{bac}$ \\
\hline A4 $(n=9)$ & $21.59 a$ & $2.34 \mathrm{~b}$ & $37.74 \mathrm{ba}$ & 7.51a & $7.42 \mathrm{a}$ \\
\hline E2 $(n=9)$ & $21.38 a$ & $3.06 \mathrm{~b}$ & $36.24 \mathrm{ba}$ & $7.77 a$ & $6.96 \mathrm{bac}$ \\
\hline$E 4(n=9)$ & $21.85 a$ & $2.88 \mathrm{~b}$ & $35.74 \mathrm{ba}$ & $7.23 a$ & $7.23 \mathrm{ba}$ \\
\hline$S(n=9)$ & $21.40 a$ & $2.13 b$ & $36.17 \mathrm{ba}$ & $7.61 a$ & $5.61 b$ \\
\hline$A 2 S(n=9)$ & $21.98 a$ & $2.37 \mathrm{~b}$ & $37.65 a$ & $7.46 a$ & $6.37 \mathrm{bdc}$ \\
\hline A4S $(n=9)$ & $21.35 a$ & $2.55 b$ & $37.51 \mathrm{a}$ & $7.65 a$ & $6.24 d c$ \\
\hline E2S $(n=9)$ & $21.23 a$ & $3.16 \mathrm{~b}$ & $34.90 \mathrm{~b}$ & $7.58 \mathrm{a}$ & $6.60 \mathrm{bac}$ \\
\hline E4S ( $n=9)$ & $21.28 \mathrm{a}$ & $2.83 \mathrm{~b}$ & 35.92ba & $7.93 a$ & 7.04bac \\
\hline$C(n=9)$ & $21.48 a$ & $4.85 a$ & $36.03 \mathrm{ba}$ & $8.82 b$ & $5.68 \mathrm{~d}$ \\
\hline $\mathrm{SE}^{5}$ & 1.67 & 0.28 & 0.6 & 0.55 & 0,30 \\
\hline \multicolumn{6}{|l|}{ Shrimp species ${ }^{6}$} \\
\hline A. foliacea $(n=30)$ & $19.92 b$ & $3.50 \mathrm{a}$ & $31.51 \mathrm{c}$ & $13.64 a$ & $8.80 a$ \\
\hline P. edwatdsi $(n=30)$ & $24.86 a$ & $3.12 \mathrm{a}$ & $43.25 a$ & $7.40 \mathrm{~b}$ & $7.42 b$ \\
\hline M. hathor $(\mathrm{n}=30)$ & $19.45 b$ & $2.24 \mathrm{~b}$ & $34.91 b$ & $0.96 c$ & $3.53 c$ \\
\hline $\mathrm{SE}^{5}$ & 1.67 & 0.28 & 0.6 & 0.55 & 0,30 \\
\hline \multicolumn{6}{|l|}{$\begin{array}{l}\text { Storage time } \\
(\text { day })^{7}\end{array}$} \\
\hline $0(n=30)$ & $4.17 c$ & $0.98 c$ & $33.94 b$ & $7.96 a$ & $8.28 c$ \\
\hline $2(n=30)$ & $20.30 \mathrm{~b}$ & $2.19 b$ & $37.49 a$ & $7.02 b$ & $6.61 b$ \\
\hline $4(n=30)$ & $39.74 a$ & $5.68 a$ & $38.23 a$ & $7.17 \mathrm{~b}$ & $7.86 a$ \\
\hline $\mathrm{SE}^{5}$ & 1.67 & 0.28 & 0.6 & 0.55 & 0.3 \\
\hline
\end{tabular}

1 Means within the same factor and the same column with different letters $(a, b$, $c, d)$ are different $(p<0.01)$.

$2 \mathrm{mg} / 100 \mathrm{~g}$.

3 Each number represents the average value of each parameter for all samples of the same treatment

4 E2= Erythorbic acid (2\%); E4= Erythorbic acid (4\%); A2= Ascorbic acid (2\%); A4= Ascorbic acid (4\%); S= Sodium metabisulphite; E2S=E2 + S; E4S=E4 + S; A2S=A2 $+\mathrm{S} ; \mathrm{A} 4 \mathrm{~S}=\mathrm{A} 4+\mathrm{S} ; \mathrm{C}=$ Control

$5 \mathrm{SE}=$ Standard Error

6 Each number represents the average value of each parameter for all samples of the same shrimp species.

7 Each number represents the average value of each parameter for all samples with the same storage time.

\subsection{Discussion}

It has been determined that metabisulphite is the best application for inhibition of melanosis. Bisulphites show competitive inhibition by binding sulfhydryl groups of the active part of the enzyme polyphenol oxidase. On the other hand, bisulfite inhibition depends on the reaction of the sulphides with the quinones and results in the formation of irreversibly inhibited sulphokinone forms of polyphenol oxidase (Kim et al., 2000). This indicates why the metabisulphite application was the best.

Reducing agents such as ascorbic acid and erythorbic acid are reported to be the best alternative for sulphide. They have been used to prevent blackening in vegetables and fruits. Sliced oyster mushrooms treated with the chemical 
preservatives sodium erythorbate and citric acid and stored in MAP at $2^{\circ} \mathrm{C}$ delayed firmness, weight loss and change of colour (Ventura-Aguilar et al., 2017). Ascorbic acid (1 to 1.5\%) was found very effective in considerably reducing enzyme browning in apple slices (El-Shimi, 1993). Sodium erythorbate and its combinations with sodium acid sulphate and citric acid were the most effective in inhibiting browning in sliced potato (Mosneaguta et al., 2012). For shrimps, first time these reducing agents were used in our study, these reducing agents were used in our study. For this reason, this study could not compare with any study. In our study, ascorbic acid and erythorbic acid were effective when used combined with sodium metabisulphite. This result suggests that the use of these reducing agents will reduce the need for sulphide. Concentrations of ascorbic acid and erythorbic acid were also effective in preventing melanosis. Further studies may produce better results with different concentrations.

Melanosis formation varies according to species. Factors such as moulting cycle, harvesting, transport, and capture methods that stimulate the defence mechanism to promote the formation of melanosis (Gonçalves \& Oliveira, 2016). Moreover, it is stated that in crustacean the intensity of melanosis, the point of beginning and the rate of spread differ among species (Gomez-Guillen et al., 2005). The reason this difference is reported as differences in substrate and enzyme concentration by some authors (Benjakul et al., 2005; Nirmal and Benjakul, 2012). In some species, PPO activity is faster than others. PPO activity in deepwater pink shrimp was found to be faster than white shrimp and melanosis spread was slower in black tiger shrimp (Montero et al., 2001). The same authors have reported that this difference in melanosis development may be due to habitat difference. In our study, melanosis in $P$. edwardsi developed very little. Even, in some applications melanosis not observed completely up to 2nd day. Plesionika edwardsi is a marine species with a wide distribution in low latitudes. It is found at depths between 54 and $700 \mathrm{~m}$. P. edwardsi used in our research was caught with trawl at a depth of $200-400 \mathrm{~m}$. On the other hand, the highest melanosis scores were observed in $M$. hathor. In our study $M$. hathor were caught in front of Aksu stream and Beşgöz creek in the Gulf of Antalya at 10-50 m depths. Although studies have been conducted on the prevention of melanosis in other shrimp species, no such studies have been done for three different species of (Aristaeomorpha foliacea, Plesionika edwardsi and Melicertus hathor) used in our study. Therefore, our study will provide information on melanosis development in these shrimp species as well as shed light on the studies to be done with these shrimp species in the future.

In a previous study, it was reported that the treatment with $50 \mathrm{~g} / \mathrm{kg}$ sulphide together with citric acid and chelates inhibited the melanosis of shrimps (Parapenaeus longirostris) for at least one week during the cold storage (Gomez-Guillen et al., 2005). In a study tiger prawns (Marsupenaeus japonicus) from aquaculture were treated with 4-hexylresorcinol $(0.1 \%$ and $0.05 \%$ ) in combination with organic acids (citric, ascorbic, and acetic) and chelating agents EDTA (ethylenediaminetetraacetic acid) and disodium dihydrogen pyrophosphate. Prawns with no additive and treated with commercial sulphite formulation were used as control. At the end of the study, it was found that prawns treated with sulphite-based formula presented the lowest score of melanoses up to 8 days (Martinez-Alvarez et al., 2005). The results of our study were different with shorter acceptability times. The differences between the results of our study and those in the literature may be due to the differences in shrimp species and antimelanotic agents used and also the difference in perception of the panellists in sensory analysis.

TVB-N is one of the most commonly used chemical methods for determining the quality of seafood products. TVB$\mathrm{N}$ (mg per $100 \mathrm{~g}$ meat) was reported to occur at an advanced stage of deterioration in fresh and frozen seafood (Ludorf \& Meyer, 1973). The highest amount of TVB-N for shrimp to be acceptable has been reported as $30 \mathrm{mg}$ per $100 \mathrm{~g}$ shrimp (Shamshad et al., 1990; Mendes et al., 2005). According to the results of our study, while the TVB-N limit values were not exceeded on day 0 and day 2 in all species, it was seen that the limit values were exceeded in some species and some application groups on day 4 .

Measurement of TMA-N content is important as it shows the level of microbial degradation in fresh seafood products. The acceptability limit of shrimp TMA was reported to be $5 \mathrm{mg}$ per $100 \mathrm{~g}$ (Shamshad et al., 1990; Cobb et al., 1973; Zeng et al., 2005; Okpala, 2004). However, some researchers have suggested different limits for different shrimp species. The TMA-N values did not exceed the limit values of the application groups, except for the values at the end of storage of some applications. The higher TVB-N and TMAN- values in control group compared to application groups shows that ascorbic acid and erythorbic acid are effective in maintaining the quality of shrimp. In a study applied organic acids to shrimps (Penaeus japonicus), the initial TVB-N value of $18.29 \mathrm{mg}$ per $100 \mathrm{~g}$ exceeded the limit value in control and acetic acid treated groups during the storage at $+4^{\circ} \mathrm{C}$. In another study, the TVB-N value of shrimp (Palaemon adspersus) was determined to be $44.64 \mathrm{mg}$ per $100 \mathrm{~g}$ at the end of the 5th day during the cold storage. It was reported that the raw shrimps could be stored for 2 days in cold storage (Erdem \& Bilgin, 2004). In deep water pink (Parapenaeus longirostris) and narwal shrimp (Parapandalus narval) the initial TVB- $\mathrm{N}$ value of $29 \mathrm{mg}$ per100 $\mathrm{g}$ reached the values of $35.09 \mathrm{mg}$ per $100 \mathrm{~g}$ and $35.85 \mathrm{mg}$ per 100 $\mathrm{g}$ at the end of storage respectively. It is thought that in our study the low initial TVB-N content and the differences with other studies may be caused by shrimp type, shrimp catching method and catching area, antimelanotic agent type, applied concentration and application method.

In the colour analysis, an increase in $L^{*}$ indicates an increase in brightness or whiteness, and a decrease in $L^{*}$ indicates an increase in darkness, the $a^{*}$ value indicates redness and $b^{*}$ value indicates yellowness. The reason for the low $a^{*}$ value in the control group is thought to be due to the bleaching effect of immersion solutions. The lowest $b^{*}$ value determined in the sulphite treated group means that the addition of sodium metabisulphite decreases the yellowness. The reason that the lowest $a^{*}$ value is determined for $M$. hathor and the highest a * value for $A$. foliacea is intense red colour of $A$. foliacea, called "red shrimp", and pale appearance of $M$. Hathor. The development of melanosis caused shrimp to decrease in $L^{*}$ value (brightness) and decrease in a * value (redness).

\section{Conclusions}

Although the antimelonotic effect of erythorbic acid and ascorbic acid were not as much as sodium metabisulphite, it was observed that they are as effective as sulphite when they are combined with sodium metabisulphite. It has also been shown that the use of these reducing agents (ascorbic and erythorbic acid) can reduce the need for sodium metabisulphite. Ascorbic acid and erythorbic acid and these shrimp species were used for the first time in this study. These results not only identify ascorbic and erythorbic acids as new 
melanosis inhibitors for shrimps, but also provide information on the development of melanosis in these shrimp species.

\section{Bibliography}

Benjakul, S., Visessanguan, W., Tanaka, M., 2005. Properties of phenoloxidase isolated from the cephalothorax of kuruma prawn (Penaeus japonicus). Journal of Food Biochemistry, 29: 470-485.

Benjakul, S., Visessanguan, W., Tanaka, M., 2006. Inhibitory effect of cysteine andglutathione on phenoloxidase from kuruma prawn (Penaeus japonicus). Food Chemistry, 98: 158-163.

Clark, A.C., Vestner, J., Barri, C., Maury, C., Prenzler, P.D., Scollary, G.R., 2009. The influence of stereochemistry of antioxidants and flavanols on oxidation processes in a model wine system: Ascorbic acid, erythorbic acid, (+)catechin and ()-epicatechin. Journal of Agricultural and Food Chemistry, 58(2): 1004-1011.

Cobb, B.F., Vanderzant, C., Thompson, C.A., Custer, C.S., 1973. Chemical characteristics, bacterial counts and potential shelf-life of shrimp from various locations on the northwestern Gulf of Mexico. Journal of Milk and Food Technology, 36: 463-468.

El-Shimi, M.M., 1993. Control of enzymatic browning in apple slices by using ascorbic acid under different conditions. Plant Foods for Human Nutrition, 43: 71-76.

Erdem, E.M., Bilgin, S., 2004. Research on the changes in quality of shrimp (Palaemon adspersus rathke, 1837), which is preserved at refrigerator temperature in cooked and raw. Firat University Journal of Science and Engineering, 16(4): 687-694 (in Turkish).

Erkan, N., Ozden, O., Alakuvak, U.D., Tosun, Ş.Y., Varlık, C., Baygar, T., 2007. Determination of sodium metabisulphide level of shrimp sold in Istanbul. Journal of Fisheries Science, 1(1): 26-33.

Golan-Goldhirsh, A., Whitaker, J.R., Kahn, V. (1984). Relation between structure of polyphenol oxidase and prevention of browning. Advances in Experimental Medcine and Biology, 177: 437-456.

Gonçalves, A.A., Oliveira, A.R.M., 2016. Melanosis in crustaceans_A review. LWT-Food Science and Technology, 65: 791-799.

Gomez-Guillen, M.C., Martínez-Alvarez, O., Llamas, A., Montero, P., 2005. Melanosis inhibition and $\mathrm{SO}_{2}$ residual levels in shrimps (Parapenaeus longirostris) after different sulphite-based treatments. Journal of the Science of Food and Agriculture, 85(7): 1143-1148.

Kim, J., Marshall, M.R, Wei, C., 2000. Polyphenoloxidase. In: N.F. Haard, B.K. Simpson (Eds.) Seafood enzymes: Utilization and influence on postharvest seafood quality, Marcel Dekker New York, pp 271-315.

Ludorf, W., Meyer, V., 1973. Fische und Fischerzeugnisse. Paul Parey Verlag, Berlin, Hamburg, 309 p.
Martinez-Alvarez, O., Lopez-Caballero, M.E., Montero, P. Gomez-Guillen, M.C., 2005. A 4-hexylresorcinol based formulation to prevent melanosis and microbial growth in chilled tiger prawns (Marsupenaeus japonicus) from aquaculture. Journal of Food Science, 70: M415-M422.

Mendes, R., A, Pestana, J., Pestana, C., 2005. Indole production and deepwater pink shrimp (Parapenaeus longirostris) decomposition. European Food Research and Technology, 221, 320-328.

Montero, P., Avalos, A., Perez-Mateos, M., 2001. Characterization of polyphenol oxidase of prawns (Penaeus japonicus) alternatives to inhibition: Additives and high-pressure treatment. Food Chemistry, 75: 317324.

Montero, P., Martínez-Alvarez, O., Gomez-Guillen, M.C., 2004. Effectiveness of onboard application of 4hexylresorcinol in inhibiting melanosis in shrimp (Parapenaeus longirostris). Journal of Food Science, 69(8): C643-C647.

Mosneaguta, R., Alvarez, V., Barringer, S.A., 2012. The effect of antibrowning agents on inhibition of potato browning, volatile organic compound profile, and microbial inhibition. Journal of Food Science, 77(11): 1234-1240.

Nirmal, N.P., Benjakul, S., 2012. Biochemical properties of polyphenoloxidase from the cephalothorax of Pacific white shrimp (Litopenaeus vannamei). International Aquaculture Research, 4(1): 6-13.

Okpala, C.O.R. (2014). Investigation of quality attributes of icestored Pacific white shrimp (Litopenaeus vannamei) as affected by sequential minimal ozone treatment. LWT Food Science and Technology, 57: 538-547.

Osuga, D., Van der Schaaf, A., Whitaker, J.R., 1994. Control of polyphenol oxidase activity using a catalytic mechanism. In: R.Y. Yada, R.L. Jaclunan \& J.J. Smith (Eds.) Protein Structure-Function Relatiomhips in Foods, Blackie Academy and Professional, Glasgow, pp 62-88.

Otwell, W.S., Marshall, M.R., 1986. Screening alternatives to sulphating agents to control shrimp melanosis (black spot). Florida Sea Grant Technical Paper, 46: 1-20 (1986).

Santerre, C.R., Cash, J.N., Vannoman, D.J., 1988. Ascorbic acid / citric acid combinations in the processing of frozen apples slices. Journal of Food Science, 56: 257-259.

Sapers, G.M., Ziolkowski, M.A., 1987. Comparison of erythorbic acid and ascorbic acids as inhibitors of enzymatic browning in apples. Journal of Food Science, 52(6): 1732-1733.

Sapers, G.M., Hicks, K.B., Phillips, J.G., Garzarella, L., Pondish, D.L., Matulaitis, R.M., McCormack, T.J., Sondey, S.M., Seib, P.A., Ei-Atawy, Y.S., 1989. Control of enzymatic browning in apple with ascorbic acid derivatives, polyphenol oxidase inhibitors, and complexing agents. Journal of Food Science, 54: 997-1002. 
Sapers, G.M., Garzarella, L., Pilizota, V., 1990. Application of browning inhibitors to cut apple and potato by vacuum and pressure infiltration. Journal of Food Science, 55: 1049-1053.

Shamshad, S.I., Nisa, K.U., Riaz, M., Zuberi, R., Quarri, R.B., 1990. Shelf life of shrimp (Penaeus merguiensis) stored at different temperatures. Journal of Food Science, 55: 1201-1205.

Simpson, B.K., Marshall, M.R., Otwell, W.S., 1987. Phenoloxidase from shrimp (Penaues setiferus): Purification and some properties. Journal of Agricultual and Food Chemistry, 35: 918-921.

Schormüller, J., 1968. Handbuchder Lebensmittelchemie, Band III/2. Springer-Verlag, Berlin, Heidelberg, New York, pp 1482-1537.

Sokal, R.R., Rohlf, F.J., 2012. Biometry: The principles and practice of statistics in biological research (4th ed.). W.H. Freeman and Co., New York, pp 119-177.

Ventura-Aguilar, R.I., Colinas-Leon, M.T., Bautista-Banos, S., 2017. Combination of sodium erythorbate and citric acid with MAP, extended storage life of sliced oyster mushrooms. LWT - Food Science and Technology, 79: 437-444.

Zeng, Q.Z., Thorarinsdotti, K.A., Olafsdottir, G., 2005. Quality changes of shrimp (Pandalus borealis) stored under different cooling conditions. Journal of Food Science, 70 (7): 459-446. 